\title{
Lean Manufacturing: Trends and Implementation Issues
}

\author{
Benjamin Durakovic ${ }^{1}$, Rukiye Demir ${ }^{1}$, Kemal Abat $^{1}$, Celal Emek $^{1}$ \\ ${ }^{1}$ Industrial Engineering, International University of Sarajevo
}

\begin{tabular}{l}
\hline Article Info \\
\hline Article history: \\
Received March 25, 2018 \\
Revised May 22, 2018 \\
Accepted June 10, 2018 \\
\hline
\end{tabular}

Keyword:

Lean manufacturing; Lean implementation;

Trends; Lean issues;

Competitive advantage

\begin{abstract}
Many manufacturing cost reduction initiatives have been introduced over past three decades including lean manufacturing. Waste reduction and efficiency improvement are the main objectives of this initiative. It is developed from a set of tools and techniques and can fit nicely in cost focus or cost leadership competitive advantage strategies. But, keeping competitive advantage under the market circumstances are getting harder with growth of production quantity and product diversity. Therefore, paper's focus is lean manufacturing implementation trends and issues within the various manufacturing sector. Successes and failures of implementation of lean manufacturing in some industries are discussed. It was found that lean principles are good source of competitive advantage, it is applicable for many industries and its expansion and discussion are significantly progressing. The biggest threat in implementing lean is lack of understanding the concept but those who engage consultants were more successful.
\end{abstract}

\section{Corresponding Author:}

Benjamin Durakovic,

Industrial Engineering, International University of Sarajevo,

Hrasnička cesta 15 ,

71000 Sarajevo, Bosnia

Email: bdurakovic@ius.edu.ba

\section{Introduction}

The future of the manufacturing industry is the lean manufacturing and lean practice is one of the best methods used by manufactures around the world to increase their competitiveness [1]. Lean manufacturing is set of methods and techniques developed by engineers of Toyota and it is very popular in today's world companies to increase value of product though waste elimination. Managers attempt to increase productivity and eliminate waste by applying lean tools such as quality [2], cost, just-in-time (JIT) delivery and continuous improvement to produce with higher quality, JIT delivery and to be cost efficient. Lean manufacturing is simple, flexible, ergonomic, compact, low cost, proper fit, green and requires less energy [3].

The basis of lean manufacturing can be found in the Japanese company of TOYOTA. Lean manufacturing is a successor of Toyota Production System (TPS). The creator of the system was Sakichi Toyoda and his sons: Kiichiro Toyoda and Eiji Toyoda as well as Taiichi Ohno. Sakichi Toyoda was working in Textile industry, he invented a motor-driven loom with a specialized mechanism devised to stop in case of breaking of the thread. This mechanism pioneered Jidoka (automatization with human manufacturing). In 1929, Kiichiro Toyoda went to the USA and was impressed by Ford production system and Kiichiro Toyoda decided to apply solutions which he learned in the USA [4]. Taiichi Ohno was a manufacturing engineer and was working on TPS in the 1940 and carried on its improvement in the late 1980s by the advancements in computers [5]. Lean manufacturing is not only applicable for automotive industry, it can be applied many other industries. Lean manufacturing spread rapidly in all over the world. Manufacturers implemented this method in order to 
eliminate and minimize the waste. There are initiatives combining Lean philosophy with six sigma [6], known as Lean Six Sigma philosophy. Basically, lean concept tries to remove weaste ("seven types of vaste") while six sigma tries to reduce error [7], which has positive impact on innovation [8].

There are many publications on this topic published by various researchers from different countries. These publications are related to distinct industry areas. Mainly these publications show readers implementation of lean manufacturing and its methods. The number of publications in this field over past three decades is shown in Figure 1.



Figure 1: Number of publications per year

Figure 1 shows the number of publications about lean manufacturing in each year between 1991 and 2017. These data is taken from Scopus and we can see from the table, number of publications started to increase especially after 2002. As it shown in the Figure 1 there is linear trend from 1991 to 2002. Between 2002 and 2005 , there is a huge increase in number of articles that means lean manufacturing became popular research topic. After 2005, there is slight decrease and the numbers follow linear trend between 2006 and 2012. As many companies from many fields try to implement lean, the popularity of lean increases lately, so do number of publications.

Regression analysis is conducted to forecast number of next five years' publication based on historical numbers. Regression analysis where dependent variable $\mathrm{y}$, which is number of publications and independent variable $\mathrm{x}$ is years, and shown in Table 1:

Table 1: Regression table

\begin{tabular}{rrrrrrrrr}
\hline & Coefficients & $\begin{array}{r}\text { Standard } \\
\text { Error }\end{array}$ & t Stat & P-value & Lower 95\% & Upper 95\% & $\begin{array}{r}\text { Lower } \\
\mathbf{9 5 . 0 \%}\end{array}$ & $\begin{array}{r}\text { Upper } \\
\mathbf{9 5 . 0 \%}\end{array}$ \\
\hline Intercept & -24132.95 & 1845.05 & -13.07 & $1.11 \mathrm{E}-12$ & -27932.9 & -20333 & -27932.9 & -20333 \\
Year & 12.106227 & 0.92 & 13.14922 & $9.87 \mathrm{E}-13$ & 10.21005 & 14.0024 & 10.21005 & 14.0024 \\
\hline
\end{tabular}

As we can see from Table 1, regression equation is; Number of Publications $=-24132.95+$ $12.106227 *$ Year and by substituting Year= 2018, 2019, 2020, 2021 and 2022 into regression equation, forecasted values for these years are 298, 310, 322, 334 and 346 respectively. It is expected that a slight increase of publications will appear. It means lean manufacturing will remain as a popular topic in following years too. 
The number of publications per subject area is shown in Figure 2. There are almost 30 different areas from engineering to neuroscience and that means lean manufacturing is applicable for many various industries.



Figure 2: Number of Publications per Subjected Area

Figure 2 represents number of publications about lean manufacturing per subjected areas and $40.265 \%$ of the publications covers engineering area. So based on the data shown on Figure 2, it can be concluded that engineering is the most common area that lean manufacturing is applied. Business, management and accounting area has $17.813 \%$ of publications and $10.539 \%$ of publications until today are about implementations of lean manufacturing in computer science area. Also decision sciences has $8.103 \%$ and material science has $4.938 \%$ of publications. It can be said that, almost $80 \%$ of publications cover these 5 areas. Other fields are also shown on the Figure 2 and there are $0.033 \%$ undefined fields.

The number of publications sorted by per countries is shown in Figure 3. There are more than 40 countries which lean manufacturing publications published. US has the biggest percentage which means it is common and popular in the US.

The minimum number of publication is 10 for the countries that take place in Figure 3, for the other countries the total percentage of publication about lean manufacturing is $4.53 \%$. US has the biggest contribution with $34.31 \%$ of publications, which is more than 1000 publications. India has $10.9 \%$, UK has $6.8 \%$, Brazil has $4.87 \%$ and Malaysia has $4.52 \%$ of publications around the world. Almost $50 \%$ of publications are written in US, India and United Kingdom. US is prior country for lean manufacturing so it is still popular in the USA.

The scope of this project is to explain common lean implementations issues and methods in various manufacturing sectors. The aim of this paper is to show and explain common lean principles and tools that are known and tried to be applied by many companies. Threads, challenges and opportunities of lean manufacturing are presented in this work. In order to achieve this goal almost 80 publications from different countries was examined and analyzed in details. These articles were demonstrated by graphs according to their years and published countries. Also, the advantages and impacts of lean manufacturing methods was clarified briefly. The outcomes of the lean manufacturing methods were stated as a conclusion.

While lean manufacturing is popular and many companies try to apply it, lack of information about lean performance and its measurements will cause to the failure of lean practices [9]. For example, it is concluded 
that despite lean principles and practices are quite popular among Lithuanian companies, evidence on adoption motives and impacts of lean production is very scarce because of lack of information of lean practices [10].

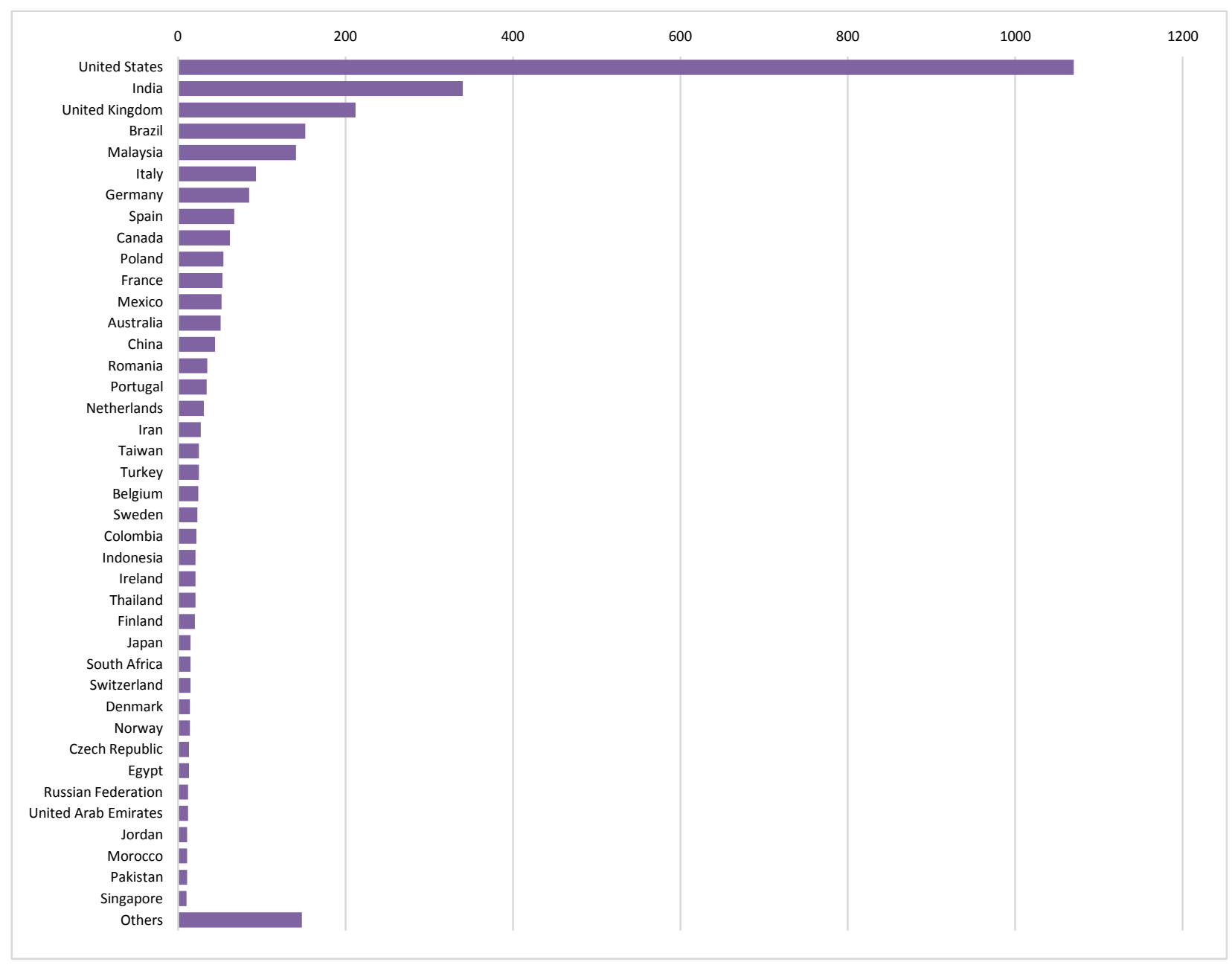

Figure 3: Number of publications per country

This study will present a qualitative briefing and review in order to understand the development of lean application and will point out the ergonomic issues that occur after the lean acceptance. Then they found out that the differences between lean theory and lean practice, the employees needs for feedback and direct involvement in the company, stress reduction in lean manufacturing through reporting all misunderstandings, the inside collaboration between employees and managers [11]. Antonio Sartal, Josep Llachb, Xosé H. Vázquezc, Rodolfo de Castro analyses Environmental and Information Technologies (ET\&IT) in the capability of Lean Manufacturing (LM) to achieve improved industrial performance. In their study, they tested hypotheses in a multi-sectoral sample of 763 factories among 5 European countries. They found that Lean Manufacturing practices triggered IT\&ET implementation because of competitive requirements and technology-enabled capabilities [12]. In this research authors focusing on constraints on the use of the Web to foster leanness are discussed and recommendations for integrating the Internet into production systems offered. Then they found that, the Internet is a perfect tool for accomplishing the lean supply chain with its open, easy, and cheap access [13].

Lean Production is generally known and accepted in the industrial area. The fourth Industrial Revolution provides having a smart connection of machines, products, components, properties, individuals and ICT systems in the whole value chain to have a new generation smart factory. [14]. Steve and Mel encourage the top managers to take an action and to start using lean manufacturing in their business. They have listed the important facts while implementing lean manufacturing, and suggested to have a lean consultant, to be able to get the required information for the implementation process. The authors mentions about the benefits of the 
change [15]. Teerasak, Daniel, Amrik, Brian, Andri, and Cheng investigated the effect of manufacturing technologies and lean practices on operational performance. The authors concluded that the manager abilities are more important than the manufacturing system. When manager skills increase, the manufacturing technique begins to become more important [16]. Sundar, Balaji, and Kumar defined the meaning of lean manufacturing and how a firm, whether it is service oriented or manufacturing oriented, should be implementing lean manufacturing into their jobs. The authors mention about the importance of using value stream mapping, cellular manufacturing, and SMED, and pull system while implementing the lean. They have mention 19 elements of the lean manufacturing, and say that most of the firms, which want to implement lean, use only two or three elements of lean manufacturing. This issue makes the application even harder and unsatisfying at the end of the production, because lean manufacturing becomes stronger and reliable as we use most of the elements[17].

\section{Lean Principles and Tools}

Lean has important effect on increasing energy productivity in manufacturing. Figure 4 shows most common lean principles and tools. Lean principles increases productivity, efficiency, effectiveness and saves time by reducing wastes, value stream mapping [18], standardizing work, just in time principle, continuous improvement (Kaizen) [19] and by other lean tools. Not all principles are applicable for all sectors and industries, which is why firstly analyzing and measuring is essential [20].

\begin{tabular}{ll}
\hline - Just in Time & $\bullet$ Poka-Yoke \\
- Kanban & $\bullet$ Waste Elimination \\
- Value Stream Mapping & $\bullet$ Standardized Work \\
- $5 \mathrm{~S}$ & $\bullet$ Autonomation \\
Takt-time & $\bullet$ PDCA \\
\hline
\end{tabular}

Figure 4: Lean Principles and Tools

While lean manufacturing is popular and most companies attempt to implement it, lack of a clear understanding of lean performance and its measurements will cause to the failure of lean practices. It is not possible to manage lean without measuring its performances. A quantitative model to measure the lean performance of manufacturing systems is introduced that managers and decision makers can easily analyze the effectiveness and identify the potential opportunities for improvement [9] . Productivity measures can have impacts on existing Lean Production Systems [21]. And lean principles sometimes fail because leaders often lack a map of their own organization. Lean brain theory that considers organizations as networks with organizational structure, functional connectivity and effective dynamic patterns is introduced to provide leaders a wider picture [22].

Companies searched the ways to improve quality and efficiency and at the same time to reduce cost and lead time. They managed it by lean manufacturing principles and even tough quality is one of the most important priorities of lean principles, quality and lean are frequently organized as separated and disintegrated departments. A case study was done in three Norwegian manufacturing firms to show that a good integration of lean and quality requires two necessary conditions. First, a high level of process maturity is important. Second, the production systems themselves also need time to mature [23].

And cultural influences play an important role in the interpretation and implementation of lean manufacturing critical success factors [24]. In a case study, a traditional production model transformed to lean manufacturing model by reducing wastes, standardizing works, internal logistics, workplace designing and changing layout in an electronics assembly line. With lean principles, manpower reduced as $40 \%$, and $30 \%$ of floor area is saved, and delivery time is reduced [25]. It is examined that the daily work practices at an organization that successfully incorporates lean production practices into the organizational culture, and reveals a pattern of practices used by managers in their daily work [26]. 
As it stated earlier, lean has taken its place in health care industry, lean health care approach in applied in many health industries. Lean thinking in health is a management model with potential to improve the management and core process performance indicators, the organizational structure, and system outcomes. Some branches like emergency medicine, drug dispensing process in the health care sector can achieve high level of success by using this approach [27]. Lean improvements are also applied and adapted in healthcare service delivery chains $[28]$.

In the following sections, some of common lean principles are explained briefly with some application examples.

\subsection{Just in Time (JIT)}

Just in time is a popular inventory model and a common lean principle that is used in supply chain to make sure that it is provided to produce right amount of products at the right time and satisfy quality requirements [29]. And it consists of supplying of right and proper materials for the system in the right quantity, place, time, position, sequence and cost [30]. The benefits of JIT can be stated as increase in productivity, reduction of total production cost, improvement the quality process, and reduction in waste and reworks, which results in an increase in production quality [31].

There is a study about integration of lean systems in the design of a sustainable supply chain model. It is described the lean manufacturing and supply chain management in detailed and how to combine them using various lean manufacturing tools in order to increase the sustainability of the work and the environment [32].

\subsection{Kanban}

Kanban is a common lean principle that has a goal of minimum inventory at any time under the philosophy of that material will not be produced or moved until a customer sends the signal to do so[33]. So in that system, production will continue if there is an available demand for the product. Kanban system is also an essential lean tool that supports tracking of material, processes and workstations, by making it easier for employees to determine the information and it reduce the cycle time [34]. Kanban system is successfully implemented in the Japanese companies, because Kanban saves costs by eliminating over production, developing flexible work stations, reducing waste and scrap, minimizing the waiting times and logistics costs; thus reducing the inventory stock levels and overhead costs [33].

\subsection{Kaizen}

Kaizen is a Japanese word that has meaning of 'continuous improvement' and it is set of practices that are focused on continuous quality improvement[2]. The process of kaizen is the analysis of the problem and the implementation of a solution with current, real-time reassessment. When performed properly, kaizen not only eliminates unnecessary work but teaches people a systematic, scientific method for identifying and eliminating waste in a process [19].

Lean six sigma method to an iron ores industry is introduced to improve process capability. They first focused on wastes analysis and process capability is evaluated. Then continuous improvement program is developed for the case. First of all, there has been an analysis conducted and wastes are determined that are defects, unnecessary processing and waiting time and a continuous improvement program is developed to solve waste and defect problems [35].

\subsection{Value Stream Mapping}

Value stream mapping is the first step at applying lean and it provides a map of current state of the company. It is the map that shows value added and non-value added activities of a production line from the raw material phase to delivery to customers. This map is used to identify reasons of wastes and to identify which lean tools should be used to reduce those wastes. After applying needed lean tools, another map is developed that shows 
the future state of the company [36]. There are some examples of sectors that applied value stream mapping on Table 2.

Table 2: Application of VSM in different fields

\begin{tabular}{ll}
\hline Sectors & Source \\
\hline Food Industry & {$[37],[38]$} \\
Color Industry & {$[39]$} \\
Cover Glass Industry & {$[40]$} \\
Automotive & {$[41],[42]$} \\
Drug Development & {$[43]$} \\
Software Development & {$[44],[45],[46]$} \\
\hline
\end{tabular}

\section{5. $5 \mathrm{~S}$}

$5 \mathrm{~S}$ is a lean tool which focuses on effective work place organization and standardized work procedures [36], and it consists of 5 practices which are sort, set in order, shine, standardize and sustain. While sorting is organizing things in order, set is designing and clearly labeling where things are stored. Everything should be stored in the right place to eliminate the unnecessary time and energy for searching. Shine is keeping everything clean and neat. Standardize is documenting the work methods and sustain is building a continuous improvement procedures and stick to it [47].

The continuous implementation of $5 \mathrm{~S}$ has some benefits, such us: improving quality of products or services, clean and productive work environment, reducing cost, increasing of effectiveness and efficiency in the processes, reducing wastes: less space for storage and wasted labor time, reduced production and set-up times etc. [48].

There is a case study that shows how $5 \mathrm{~S}$ steps of lean is effective on reduction wastes, improving quality and efficiency, environmental performance and health and safety in a copper wire drawing company based in East of the National Capital Territory of Delhi, India [49].

\subsection{Waste Elimination}

Most of lean tools are based on the philosophy of elimination of wastes. Lean principles has already proven its value on making a company more profitable, by eliminating waste towards its environment and by spreading the spirit of continuous improvement among the stakeholders [50]. Lean principles are applied to remanufacturing process in four different companies to be able to increase productivity by eliminating waste of time and it is concluded that from $83 \%$ to $99 \%$ of total time is consumed by three unnecessary operations: inventory storing (before, during and after process), waiting for/collecting spare parts and waiting for information on incoming core [51]. A production-management model is analyzed that considers the possibility of implementing a reverse-logistics system and eliminating wastes for remanufacturing end-of-life products in a lean production environment [52].

\subsection{Operations Research Techniques in Lean Manufacturing}

Operations research and design of experiments (DOE) techniques can be applied in lean principles to identify most influencing factors and get an optimal design of manufacturing processes [53]. A methodology with three operations research techniques (process planning, line balancing and equipment selection) is developed and applied to lean principles to get 'optimal lean' [54]. In another research, a design support tool for new Lean production systems is presented. The design support tool consists of three elements with a strong interaction[55]. Another operations research technique, constraint identification technique that has three new methods which are flow constraint analysis, effective utilization analysis and quick effective utilization analysis, is introduced to lean manufacturing system. After the constraint is identified, appropriate decisions 
can be made on exploiting the constraint to further improve the system [56]. Another way to improve and optimize manufacturing process is

\section{Implementation and Impact of Lean Manufacturing}

After World War II, in the beginning of 1950s, manufacturers were seeking for improvement in their number of production, quality, and variability [57]. Toyota motors applied lean manufacturing into their production [58]. Lean manufacturing techniques has proven to be positively effective in most of the manufacturing fields [59], like metal industry, automotive industry, hospitals [60], textile industry, for years. Hence, most of the manufacturers wanted to adopt this manufacturing techniques to increase their financial performance [61], or the ergonomic layout of the company [62] or the sustainability of the work [63], by using Just in Time, waste reduction and detect-free production [64] techniques. Many new industries are trying to test whether lean manufacturing is applicable for their sector or not. For example, Fawaz and Jayant [65] describe a case where lean principles were adapted for the process sector for application at a large integrated steel mill. They have used value stream mapping and simulation to define the techniques that would be used, and to present the result to top managers. As a result, they have concluded that several lean manufacturing techniques like, setup reduction, $5 \mathrm{~s}$, value stream mapping, JIT, etc. are applicable for the process. The same test was made for aerospace industry, too. Engineers [66] implemented lean manufacturing to a company, which produces aerospace equipment in Indonesia. They defined risk as any event that may prevent any project or activity to achieve its objective. They focus on SQCDP, which is safety, quality, cost, delivery, and people. By using value stream mapping and SQCDP, and Delphi method, they have implemented lean manufacturing system to the company [67]. Tomcy, Steven, and Rapinder applied lean manufacturing to a project of producing plutonium-238 oxide, which is used by NASA to power deep space probes and planetary rovers. Using value stream mapping of the process and simulation, the authors indicated that in $95 \%$ confidence interval the process will exceed the required production rate of $1500 \mathrm{~g}$ [68]. Lean manufacturing is tested about the benefits of lean manufacturing in automotive industry and developed various ways to decrease the emission of a car engine. It is concluded that by applying such techniques into the engine would give a better result in long term.

However, implementing the lean manufacturing techniques is not only about how well the technique will do in the company, but also how willful the top managers are to take the risks. Lean manufacturing techniques have risks while applying to small and medium enterprises. Top managers are playing big role while facing with those risk that is why they must educate themselves in lean leadership, too [69]. A French small enterprise [70] was observed for the implementation. The researchers concluded that the managers are playing big role on the scenario. Because of the lack of method and procedure, non-functionless of an organization, and the lack of expertise, small and medium enterprises are having trouble with adapting lean manufacturing systems. Likewise, small and medium enterprises in Indonesia [71] were observed for the implementation of Kanban system. It is noted that top management commitment, vendor participation, inventory management and quality improvement are important for Kanban development. The reason of why enterprises cannot adopt lean manufacturing techniques is that ineffective inventory management, lack of supplier participation, lack of quality improvements and quality control and lack of employee participation and lack of top management commitment toward the implementation of Kanban system in the production.

Lean methodology applied in aircraft disassembling process improves efficiency by eliminating waste through the reduction of dissembling time delays [72]. And a continuous stream by choosing the optimal sequence of disassembling of parts taking into account the airplane zones. Also a high level of efficiency and quality taking into consideration various parameters of reverse supply chain. Lean manufacturing can also be applied to process manufacturing. It is showed that several lean techniques can be suitably adapted to steel industry. A simulation model is developed to evaluate basic performance measures and analyze system configurations for the managers who are uncertain about the potential outcomes and results showed that some lean techniques can be applied in steel industry successfully [36].

Tokola, Niemi and Kyrenius (2015) [73] studied how the scheduling of production changes when four conditions of Lean paradigm implemented. First, when the flow time is emphasized, the objective of the 
scheduling changes from utilization to a short flow time. Second, if local control is used, it means that the optimization is performed locally. Third, if the variation is reduced, the processing times and arrival times have less variation and, fourth, the scheduling can force the flow times to have less variation by using first-infirst-out (FIFO) sequencing. Research paper studies how these conditions should be taken into account in scheduling and which conditions should be applied.

Lean and six sigma principles can also be applied in many other sectors. Research findings showed that it is worth to use lean principles in IT sector too [74]. In another research examined the application of Lean management methods in the hotel sector. They introduced a case study in a hotel company and applied selected Lean methods. It is concluded that not all of the selected methods are suitable for hotel sector but several Lean methods have been implemented successfully [75]. Lean has been applied to healthcare industry increasingly and lean is the best understood as a means to increase productivity [76].

In lean manufacturing there are several techniques that one can use. Each one of them gives different results and different impacts. A technique used in a company, which is in textile industry, may give a different result for a company of metal industry [77]. The impact of five essential lean methods which are just in time, autonomation, kaizen, total production maintenance, and value stream mapping is tested, on four commonly utilized measures which are material use, energy consumption, non-value added activities, and environmental factors. From a data, which is collected from 250 firms which are using lean manufacturing. Conclusion was that total production maintenance is the best method of all the lean manufacturing tools. When lean is applied into metal industry to improve the quality of the manufacturing. Several lean manufacturing tools like visual control, 5s, value stream mapping, and kaizen are used. After implementation, the total processing time was reduced by $62.5 \%$, while the decrease amount on the number of motion waste is $66.53 \%$ [61] . Mark, Paul, and Sachin hypothesized the impact of lean manufacturing and environmental management on business performance, which the data collected from 309 international manufacturing firm by using AMOS. Lean manufacturing is known to have a positive impact on business performance. Hence, the authors, in this research, used environmental management, which seemed to have a negative impact on business performance, with lean manufacturing to check whether they got a better result or not. It turns out that environmental management, when used with lean manufacturing, has a positive impact on business performance. , In automotive industry [78] conducted a survey in 91 companies to be able to determine the most influential lean tools. And they concluded by survey results that 5 of 30 Lean tools are highly effective. It is stated that lean production not only successfully challenged the accepted mass production practices in the automotive industry, significantly shifting the trade-off between productivity and quality, but it also led to a rethinking of a wide range of manufacturing and service operations beyond the high-volume repetitive manufacturing environment [79]. Like in supply chain management [80], lean manufacturing applied to a three-tier spare parts supply chain, with radio frequency identification technology. The total operation time was saved $81 \%$.

\section{Trends, Challenges and Opportunities}

Lean manufacturing techniques was firstly used in automotive industry, as all other new techniques were, too. When it was successful other industries started to implement this techniques to their fields as well. Because it is a wide technique, it is suitable for most of the industries that has any kind of production or product flow, like metal industry and textile industry. Lean manufacturing technique is used by aerospace material manufacturers, too. Its trend is huge because of the outcomes of the techniques.

Lean has proven itself to be positively effective in most of the fields by reducing any kind of waste, either it is a product, time, or an action. Hence, the increase in financial performance and the sustainability of the work appear to have been inevitable. By value stream mapping technique, it is easier to see waste movement a product, or a worker, and fix it. While using techniques like Kanban, JIT, six sigma etc. value stream mapping helps a lot to see what is actually going on with the production, even to the smallest details. The technique is quite promising. Every day, the number of researches about lean manufacturing increases, and the new ideas are found that can increase the positive effects of lean while decreasing possible risks. As lean manufacturing becomes more famous, more companies will implement it. This way, new fields will be discovered in which lean can be implemented. 


\begin{tabular}{l}
\multicolumn{1}{|c|}{ TRENDS } \\
\hline -Automotive Industry \\
- Steel mill \\
- Metal Industry \\
- Supply Chain \\
- Ergonomics \\
- Hospitals \\
- Textile Industry \\
-Aerospace \\
\end{tabular}

\begin{tabular}{l}
\hline \multicolumn{1}{|c|}{ BENEFITS } \\
\hline - Reducing the waste \\
time \\
- Reducing the waste \\
product \\
- Reducing work flow \\
- Reducing work in \\
Process Inventory \\
- Increasing \\
ergonomical layout of \\
company \\
- Increasing financial \\
performance \\
- Increasing \\
sustainability of the \\
work \\
- Self improving \\
\hline
\end{tabular}
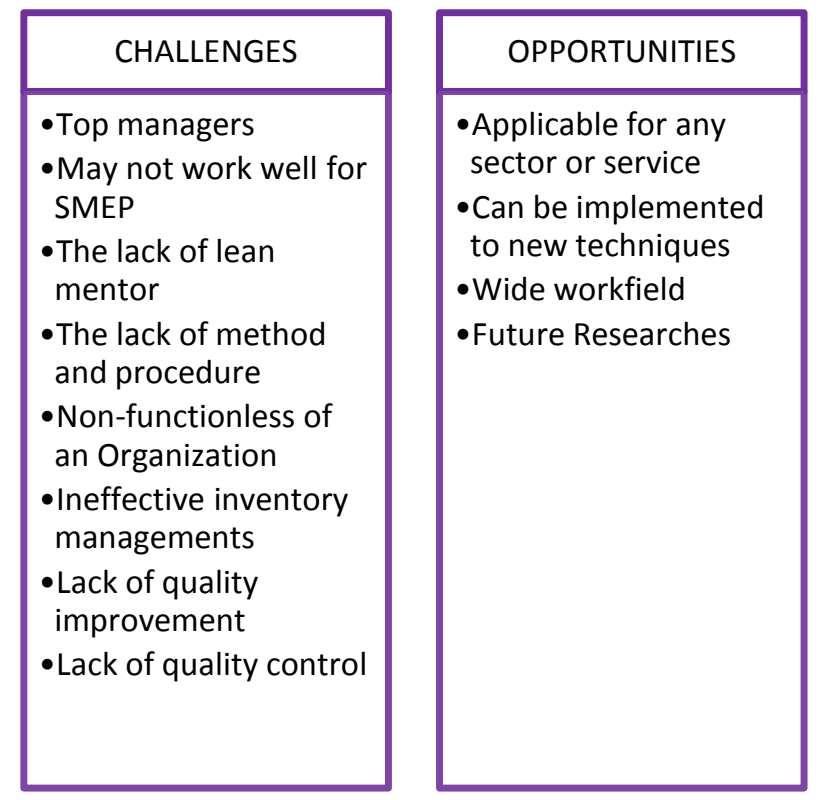

Figure 5. Summary of trens, benefits, challenges and opportunities

However, that does not mean that implementing lean will be so easy. Top managers are always playing huge role, when it comes to decision making. Most of the top managers are not willing to spend so much effort to implement lean because the outcomes of the lean varies from a company to another, and they don't know how effective it will be in their company. In order to implement lean, managers first need to find a mentor, or a lean consultant. With his help, starting from the beginning of the production line, top managers smooth away the obstacles. It is easier to say than done because even if the managers are willing to implement lean, workers may not be ready for the new system. A tutorial, that explains how the new system will work, is needed for all workers, in order to recognize and not to get lost with the production.

\section{Conclusion}

In conclusion, lean manufacturing has principles that increase value of product by eliminating of wastes and it makes a company more profitable. In this paper, common lean principles and tools that are known and tried to be applied by many companies, are explained. Also successes and failures of implementation of lean manufacturing in some industries are presented and reasons that make them (un)successful are discussed.

Lean principles are applicable in many industries. We may not apply all principles for a certain industry for example health sector but at least a few of them will make the industry more profitable. Some lean principles and tools can also be implemented in service sectors too.

Threads, challenges and opportunities of lean manufacturing are presented in this work. And it is concluded that many industries have been using lean manufacturing to get a competitive advantage for years and many of them is introduced with lean recently and implemented successfully. There are a lot of opportunities lean offers to manufacturers and implementation of lean is sometimes a necessity while competitors are taking advantage by lean. Threads are also discussed and found that lack of understanding lean could be the biggest thread in implementing lean and lean consultants or mentors can be helpful to overcome these issues.

\section{References}

[1] M. Kumar, R. Vaishya and Parag, "Real-Time Monitoring System to Lean Manufacturing," Procedia Manufacturing, vol. 20, pp. 135-140, 2018.

[2] B. Durakovic and H. Basic, "Continuous Quality Improvement in Textile Processing by Statistical 
Process Control Tools: A Case Study of Medium-Sized Company," Periodicals of Engineering and Natural Sciences, vol. 1, no. 1, pp. 39-46, 2013.

[3] J. Durkee, "Just What is 'Lean Manufacturing' Anyway?," Metal Finishing, vol. 106, no. 12, pp. 44-46, 2008.

[4] Ł. Dekier, "The Origins and Evolution of Lean Management System," Journal of International Studies, vol. 5, pp. 46-51, 2012.

[5] T. MELTON, "THE BENEFITS OF LEAN MANUFACTURING 'What Lean Thinking has to Offer the Process Industries'," Chemical Engineering Research and Design, no. 83, p. 662-673, 2005.

[6] B. Duraković and H. Bašić, "Textile Cutting Process Optimization Model Based On Six Sigma Methodology In A Medium-Sized Company," Journal of Trends in the Development of Machinery and Associated Technology, vol. 16, no. 1, pp. 107-110, 2012.

[7] H. Bašić, B. Duraković and A. Softić, "Six Sigma Model Testing in Optimizing Medium-Sized Company Production Process," Journal of Trends in the Development of Machinery and Associated Technology, vol. 16, no. 1, pp. 103-106, 2012.

[8] B. Durakovic, H. Basic and H. Muhic, "The Interrelationships between Quality Management Practices and Their Effects on Innovation Performances," in Trends in The Development of Machinery and Associated Technology TMT 2014, Budapest, 2014.

[9] F. Behrouzi and K. Y. Wong, "Lean performance evaluation of manufacturing systems: A dynamic and innovative approach," Procedia Computer Science, vol. 3 , p. 388-395, 2011.

[10] M. Vilkas, I. Koreckaja, E. Katiliute and D. Bagdoniene, "Adoption of Lean production: preliminary evidence from Lithuania," Procedia - Social and Behavioral Sciences, vol. 213, p. 884 - 889, 2015.

[11] B. Cirjaliu and A. Draghici, "Ergonomic Issues in Lean Manufacturing," Procedia - Social and Behavioral Sciences, vol. 221, p. 105 - 110, 2016.

[12] A. Sartal, J. Llachb, X. H. Vázquez and R. de Castro, "How much does Lean Manufacturing need environmental and information technologies?," Journal of Manufacturing Systems, vol. 45, p. 260-272, 2017.

[13] P. Bruun and R. N. Mefford, "Lean production and the Internet," Int. J. Production Economics, vol. 89, p. 247-260, 2004.

[14] B. Mrugalska and M. K. Wyrwicka, "Towards Lean Production in Industry 4.0," Procedia Engineering, vol. 182, p. $466-473,2017$.

[15] S. Stewart and M. Adams, "The lean manufacturing champion: reducing time and risk by encouraging risk-taking," Strategic Change, vol. 7, pp. 357-366, 1998.

[16] T. Khanchanapong, D. Prajogo, A. S. Sohal, B. K. Cooper, A. C. Yeung and T. Cheng, "The unique and complementary effects of manufacturing technologies and lean practices on manufacturing operational performance," Int. J. Production Economics, 2014.

[17] R. Sundar, A. Balajib and R. SatheeshKumar, "A Review on Lean Manufacturing Implementation Techniques," Procedia Engineering, vol. 97, p. 1875 - 1885, 2014.

[18] L. Romero and A. Arce, "Applying Value Stream Mapping in Manufacturing: A Systematic Literature Review," IFAC PapersOnLine, vol. 50, no. 1, p. 1075-1086, 2017.

[19] M. P. Knechtges and M. M. C. Decker, "Application of Kaizen Methodology to Foster Departmental Engagement in Quality Improvement," Journal of the American College of Radiology, vol. 11, pp. 11261130, 2014.

[20] A. R. R.Sundar, "A Review on Lean Manufacturing Implementation Techniques," Procedia Engineering, vol. 97, p. 1875 - 1885, 2014.

[21] P. Schnellbach and G. Reinhart, "Evaluating the Effects of Energy Productivity Measures on Lean Production Key Performance Indicators," Procedia CIRP, vol. 26 , pp. 492- 497, 2015.

[22] J. Villalba-Díez, J. Ordieres-Meré and S. Rubio-Valdehita, "The Lean Brain Theory. Brain-like Lean Manufacturing Systems," Procedia CIRP, vol. 57, p. 140 - 145, 2016.

[23] G. Ringena, S. Aschehouga, H. Holtskogb and J. Ingvaldsena, "Integrating Quality and Lean into a 
Holistic Production System," Procedia CIRP, vol. 17, p. 242 - 247, 2014.

[24] I. Alhuraish, C. Robledo and A. Kobi, "A Comparative Exploration of Lean Manufacturing and Six Sigma in terms of their Critical Success Factors," Journal of Cleaner Production, vol. 164, pp. 325-337, 2017.

[25] M.-N. Nguyen and N.-H. Do, "Re-engineering Assembly line with Lean Techniques," Procedia CIRP, vol. 40, pp. 591-596, 2016.

[26] J. Alpenberg and D. P. Scarbroughb, "Exploring communication practices in lean production," Journal of Business Research, vol. 69, no. 11, pp. 4959-4963, 2016.

[27] F. Moldovan, "New Approaches and Trends in Health Care," Procedia Manufacturing, vol. 22, pp. $947-$ 951, 2018.

[28] H. L. Tay, "Lean Improvement Practices: Lessons from Healthcare Service Delivery Chains," IFACPapersOnLine, vol. 49, no. 12, p. 1158-1163, 2016.

[29] S. Wang and B. Ye, "A Comparison Between Just-in-time and Economic Order Quantity Models with Carbon Emissions," Journal of Cleaner Production, vol. 187, pp. 662-671, 2018.

[30] N. H. A. Halim, A. Jaffar, N. Yusoff and A. N. Adnan, "Gravity Flow Rack's Material Handling System for Just-In-Time (JIT) Production," Procedia Engineering, vol. 41, p. 1714 - 1720, 2012.

[31] J. L. G. Alcaraz, A. A. Maldonado, A. A. I. G. C. Robles and G. A. Herna'ndez, "A systematic review/survey for JIT implementation: Mexican maquiladoras as case study," Computers in Industry, vol. 65, p. 761-773, 2014.

[32] K. Das, "Integrating Lean Systems in the Design of a Sustainable Supply Chain Model," International Journal of Production Economics, 2018.

[33] N. A. A. Rahman, S. M. Sharif and M. M. Esa, "Lean Manufacturing Case Study with Kanban System Implementation," Procedia Economics and Finance, vol. 7, p. 174 - 180 , 2013.

[34] C. J. Lin, F. Chen and Y. M. Chen, "Knowledge kanban system for virtual research and development," Robotics and Computer-Integrated Manufacturing, vol. 29, p. 119-134, 2013.

[35] S. Indrawati and M. Ridwansyah, "Manufacturing Continuous Improvement Using Lean Six Sigma: An Iron Ores Industry Case Application," Procedia Manufacturing, vol. 4, p. 528 - 534, 2015.

[36] F. A. Abdulmalek and J. Rajgopal, "Analyzing the benefits of lean manufacturing and value stream mapping via simulation: A process sector case study," Int. J. Production Economics , vol. 107, p. 223 236, 2007.

[37] H. D. Steura, J. Wesana, M. K.Dora, D. Pearce and X. Gellynck, "Applying Value Stream Mapping to reduce food losses and wastes in supply chains: A systematic review," Waste Management, vol. 58, pp. 359-368, 2016.

[38] N. S. @Suhadak, N. Amit and M. N. Ali, "Facility Layout for SME Food Industry via Value Stream Mapping and Simulation," Procedia Economics and Finance, vol. 31, pp. 797-802, 2015.

[39] N. K. Kasava, N. M. Yusof, A. K. Muhammad and Z. M. Saman, "Sustainable Domain Value Stream Mapping (SdVSM) Framework Application in Aircraft Maintenance: A Case Study," Procedia CIRP, vol. 26, pp. 418-423, 2015.

[40] Y. Huang and M. Tomizuka, "Production Flow Analysis through Environmental Value Stream Mapping: A Case Study of Cover Glass Manufacturing Facility," Procedia CIRP, vol. 61, pp. 446-450, 2017.

[41] D. Stadnicka and P. Litwin, "Value Stream and System Dynamics Analysis - An Automotive Case Study," Procedia CIRP, vol. 62, pp. 363-368, 2017.

[42] A. Haghighatkhah, A. Banijamali, O.-P. Pakanen, M. Oivo and P. Kuvaja, "Automotive software engineering: A systematic mapping study," Journal of Systems and Software, vol. 128, pp. 25-55, 2017.

[43] M. Heinzen, S. Mettler, A. Coradi and R. Boutellier, "A new application of value-stream mapping in new drug development: a case study within Novartis," Drug Discovery Today, vol. 20, no. 3, pp. 301-305, 2015.

[44] N. B. Ali, K. Petersen and B. B. N. d. França, "Evaluation of simulation-assisted value stream mapping for software product development: Two industrial cases," Information and Software Technology, vol. 68, 
pp. 45-61, 2015.

[45] G. A. García-Mireles, Á. Moraga, F. García, C. Calero and M. Piattini, "Interactions between environmental sustainability goals and software product quality: A mapping study," Information and Software Technology, vol. 95, pp. 108-129, 2018.

[46] H. Edison, X. Wang, R. Jabangwe and P. Abrahamsson, "Innovation Initiatives in Large Software Companies: A Systematic Mapping Study," Information and Software Technology, vol. 95, pp. 1-14, 2018.

[47] O. Omogbai and K. Salonitis, "The implementation of 5S lean tool using system dynamics approach," Procedia CIRP, vol. 60, p. $380-385,2017$.

[48] C. Veres (Harea), L. Marian, S. Moica and K. Al-Akel, "Case study concerning 5S method impact in an automotive company," Procedia Manufacturing , vol. 22, pp. 900-905, 2018.

[49] K. M. Sharma and S. Lata, "Effectuation of Lean Tool " 5 S" on Materials and Work Space Efficiency in a Copper Wire Drawing Micro-Scale Industry in India," Materials Today: Proceedings , vol. 5, p. 46784683, 2018.

[50] D. Mourtzis, P. Papathanasiou and S. Fotia, "Lean Rules Identification and Classification for Manufacturing Industry," Procedia CIRP, vol. 50, pp. 198-203, 2016.

[51] J. Kurilova-Palisaitiene, E. Sundin and B. Poksinska, "Remanufacturing challenges and possible lean improvements," Journal of Cleaner Production, 2017.

[52] S. Rubio and A. Corominas, "Optimal manufacturing-remanufacturing policies in a lean production environment," Computers \& Industrial Engineering, vol. 55, p. 234-242, 2008.

[53] B. Durakovic, "Design of Experiments Application, Concepts, Examples: State of the Art," Periodicals of Engineering and Natural Scinces, vol. 5, no. 3, p. 421-439, 2017.

[54] A. Dolgui, "Operations Research Techniques for Design and Analysis of Lean Manufacturing Systems," IFAC Proceedings Volumes, vol. 40, no. 18, pp. 11-19, 2007.

[55] I. W. De Kogel and d. i. J. J. Becker, "Development of Design Support Tool for New Lean Production Systems," Procedia CIRP, vol. 41, p. 596-601, 2016.

[56] T. Sims and H.-d. Wan, "Constraint identification techniques for lean manufacturing systems," Robotics and Computer-Integrated Manufacturing, 2015.

[57] S. Arslankaya and H. Atay, "Maintenance management and lean manufacturing practices in a firm which produces dairy products," Procedia - Social and Behavioral Sciences, vol. 207, p. 214 - 224, 2015.

[58] R. F. Aziz and S. M. Hafez, "Applying lean thinking in construction and performance improvement," Alexandria Engineering Journal, vol. 52, pp. 679-695, 2013.

[59] K. Salonitis and C. Tsinopoulos, "Drivers and Barriers of Lean Implementation in the Greek Manufacturing Sector," Procedia CIRP, vol. 57, p. 189 - 194, 2016.

[60] P. Mancosu, G. Nicolini, G. Goretti, D. De Rose, F. Franceschini, D. C. Ferrari, G. Reggiori, S. Tomatis and M. Scorsetti, "Applying Lean-Six-Sigma Methodology in radiotherapy: Lessons learned by the breast daily repositioning case," Radiotherapy and Oncology, vol. xx, pp. xxx-xxx, 2018.

[61] C. Hofer, C. Eroglu and A. R. Hofer, "The effect of lean production on financial performance: The mediating role of inventory leanness," Int. J. Production Economics, vol. 138, pp. 242-253, 2012.

[62] A. Regattieri, C. Mora and L. Botti, "Application of a mathematical model for ergonomics in lean manufacturing," no. http://dx.doi.org/10.1016/j.dib.2017.06.050 .

[63] K. Das, "Integrating lean systems in the design of a sustainable supply chain model," International Journal of Production Economics , no. 10.1016/j.ijpe.2018.01.003 , 2018.

[64] A. Regattieri, C. Mora and L. Botti, "Integrating ergonomics and lean manufacturing principles in a hybrid assembly line," Computers \& Industrial Engineering, no. http://dx.doi.org/10.1016/j.cie.2017.05.011, 2017.

[65] F. A. Abdulmalek and J. Rajgopal, "Analyzing the benefits of lean manufacturing and value stream mapping via simulation: A process sector case study," Int. J. Production Economics, vol. 107, p. 223236, 2007. 
[66] W. Widiasih, P. D. Karningsih and U. Ciptomulyono, "Development of integrated model for managing risk in lean manufacturing implementation: a case study in an Indonesian manufacturing company," Procedia Manufacturing, vol. 4, pp. 282-290, 2015.

[67] T. Thomas, S. Sherman and R. Shawhney, "Application of lean manufacturing principles to improve a conceptual 238Pu supply process," Journal of Manufacturing Systems, vol. 46, p. 1-12, (2018.

[68] P. Chiabert, G. D’Antonio, J. Inoyatkhodjaev, F. Lombardi and S. Ruffa, "Improvement of powertrain mechatronic systems for lean automotive manufacturing," Procedia CIRP, vol. 33, pp. 53-58, 2015.

[69] U. Dombrowski and T. Mielke, "Lean Leadership - 15 Rules for a sustainable Lean Implementation," Procedia CIRP, vol. 17, pp. 565-570, 2014.

[70] A. Moeuf, S. Tamayo, S. Lamouri, R. Pellerin and A. Lelievre, "Strengths and weaknesses of small and medium sized enterprises regarding the Strengths and weaknesses of small and medium sized enterprises regarding the implementation of lean manufacturing," IFAC-PapersOnLine, Vols. 49-12, p. 071-076, 2016.

[71] N. A. Abdul Rahman, S. M. Sharif and M. M. Esa, "Lean Manufacturing Case Study with Kanban System Implementation," Procedia Economics and Finance, vol. 7, pp. 174-180, 2013.

[72] O. Dayi, A. Afsharzadeh and C. Mascle, "A Lean based process planning for aircraft disassembly," IFAC-PapersOnline, vol. 49, no. 2, pp. 054-059, 2016.

[73] H. Tokola, E. Niemi and P. Kyrenius, "How Lean transformation affects scheduling," Robotics and Computer-Integrated Manufacturing, vol. 43, pp. 171- 178, 2015.

[74] A. Modi and L. Doyle, "Applicability of Lean-Sigma in IT Service Delivery System," IFAC Proceedings Volumes, vol. 45, no. 10, pp. 154-159, 2012.

[75] E. Rauch, A. Damian, P. Holzner and D. T. Matt, "Lean Hospitality - Application of Lean Management methods in the hotel sector," Procedia CIRP, vol. 41, pp. 614-619, 2016.

[76] A. D'Andreamatteo, L. Ianni, F. Lega and M. Sargiacomo, "Lean in Healthcare: a comprehensive review," Health Policy, vol. 119, no. 9, pp. 1197-1209, 2015.

[77] J. A. Garza-Reyes, V. Kumar, S. Chaikittisilp and K. H. Tan, "The effect of lean methods and tools on the environmental performance of manufacturing organisations," International Journal of Production Economics , no. doi: 10.1016/j.ijpe.2018.03.030., 2018.

[78] P. Arunagiri and A. Gnanavelbabu, "Identification of High Impact Lean Production Tools in Automobile Industries using Weighted Average Method," Procedia Engineering, vol. 97 , p. 2072 - 2080, 2014.

[79] M. Holweg, "The genealogy of lean production," Journal of Operations Management, vol. 25, pp. 420437, 2007.

[80] J. C. Chen, C.-H. Cheng and P. B. Huang, "Supply chain management with lean production and RFID application: A case study," Expert Systems with Applications, vol. 40, p. 3389-3397, 2013. 